\title{
Erratum: Geneticist seeks engineer: must like flies and worms
}

Nat. Methods 4, 463 (2007).

In the version of this editorial initially published, the development of the 'wingmachine' was improperly attributed to the University of Florida. The instrument was developed at Florida State University. The error has been corrected in the HTML and PDF versions of the article.

\section{Corrigendum: The rise of the 'projectome'}

Narayanan Kasthuri \& Jeff W Lichtman

Nat. Methods 4, 307-308 (2007).

In the version of this article initially published, the source of the electron microscopy micrograph in Figure 1 was not acknowledged. The electron micrograph was provided by Kristen M. Harris (University of Texas). 